\title{
PRINCÍPIOS EM MOVIMENTO: O APRENDIZAdO DA DANÇA CLÁSSICA INDIANA ATRAVÉS DO SISTEMA LABAN/BARTENIEFF
}

\author{
Ciane Fernandes ${ }^{1}$
}

\section{Introdução: desafios e(m) diferenças}

Este projeto teve início em 2001, quando comecei a estudar o estilo Bharatanatyam de dança clássica Indiana na Academia de Artes Cênicas Rajyashree Ramesh em Berlim. Como professora de Análise Laban de Movimento (LMA), usei o material hoje denominado de Sistema Laban/ Bartenieff para acessar uma tradição cultural tão diferente da minha. Este desafio é uma das bases do sistema: aprender com a diferença e expandir as possibilidades corporais rumo ao Domínio do Movimento(LABAN, 1978), muito além de nossas preferências e hábitos. O sistema desenvolvido pelo pioneiro e muitos de seus discípulos ao longo de quase um século é uma estrutura aberta e mutável, que não pretende estabelecer uma linguagem única. Por este motivo, venho renomeando LMA de Análise Laban em Movimento.

Através de Princípios de Movimento, a LMA pontua as diferenças e facilita a troca e o aprendizado num contexto intercultural e interartístico. Assim, este projeto utiliza a LMA sob duas perspectivas: a de uma brasileira aprendendo dança clássica indiana, e a de uma indiana revisitando sua própria formação na Índia. Os resultados desta pesquisa têm sido aplicados também em duas perspectives diversas: a de uma professora de LMA ensinando técnica de corpo para atores brasileiros, e a de uma mestra em dança clássica indiana ensinando esta técnica para dançarinos e não-dançarinos europeus (as aulas de Rajyashree Ramesh incluem europeus de vários países, mas principalmente alemães).

${ }^{1}$ Com revisão técnica em por Rajyashree

Ramesh. Ciane

Fernandes é professora da Escola de Teatro e do Programa de Pós-Graduação em Artes Cênicas da UFBA, Ph.D. em Artes \& Humanidades para Intérpretes das Artes Cênicas pela New York University e Analista de Movimento pelo Laban/ Bartenieff Institute of Movement Studies, de onde é pesquisadora associada.

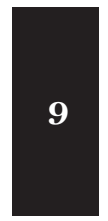


Apesar de ensinar princípios de Bharatanatyam, eu não diria que ensino esta técnica. O que ensino pode ser chamado de Técnica de corpo para a cena através do Sistema Laban/Bartenieff. Ou seja, utilizo LMA para organizar coerentemente conhecimentos técnicos diversos - inclusive Bharatanatyam na formação corporal de atores da Escola de Teatro da Universidade Federal da Bahia. Meu objetivo principal é conectar os atores com seus corpos, em relação aos outros e ao espaço, expandindo suas possibilidades de expressão e concedendo-lhes os instrumentos para aplicar este conhecimento somático no aprendizado de qualquer técnica, personagem ou contexto performático, tanto quanto na pesquisa, crítica escrita e ensino.

Já Rajyashree Ramesh ensina Bharatanatyam para dançarinos e nãodançarinos em sua academia em Berlim. Seu objetivo é formar dançarinos no contexto da tradição clássica indiana, incluindo toda sua complexidade, de dança abstrata a expressiva, teoria e canto, bem como mitologia hinduísta. Seu foco é não apenas na perfeição técnica (e posso dizer que ela é bem rigorosa neste aspecto), mas na essência do movimento enquanto integração no todo do dançarino, formas/linhas e expressividade/emoções, presente na tradição indiana. Para chegar a isso seu trabalho, nos últimos 15 anos, vem se inspirando em princípios da yoga, anatomia, terapia respiratória e, mais recentemente desde que teve contato com LMA -, usando este instrumento para facilitar o aprendizado de uma técnica tão complexa.

A partir do meu aprendizado nas aulas de Ramesh, que foi todo realizado a partir da minha experiência como analista de movimento, Ramesh percebeu que LMA pode ser facilmente associada à Bharatanatyam. Usando LMA, consegui captar a maioria de suas instruções em sala-de-aula, movendome com uma consciência interna para conectar-me com o espaço, ao invés de simplesmente copiar uma forma externa (como muitas vezes se aprende estilos de dança). Após apenas seis meses de aulas, eu já estava acompanhando as aulas dos alunos que estudavam há dois anos.

Rajyashree Ramesh vem usando esta associação para ilustrar a geometria tão difundida dos movimentos da dança clássica indiana, e demonstrar como sua relevância não reside apenas em provocar uma experiência estética no espectador, mas também em um processo de consciência corporal para o dançarino, que aprende a sentir estas linhas de dentro para fora. No ensino tradicional da dança clássica indiana na Índia, o olho do professor corrige os movimentos, sua expressividade, forma, etc. Mas nas aulas de Ramesh, a partir de seu contato com LMA através de minha colaboração, ela começou a lidar com questões como: perceber onde um movimento se inicia e como ele se desenvolve (sequenciamento), as partes que se movem e as que apóiam (Mobilidade/Estabilidade), conexões internas entre diferentes partes do corpo nos diferentes Padrões Neurológicos Básicos, etc. Isto permite que os alunos 
desenvolvam uma consciência interna daquilo que está sendo corrigido pelo olhar externo, possibilitando os objetivos tradicionais de prep aro físico, clareza de movimento e expressão, tanto quanto a abordagem contemporânea de consciência e criatividade. Com esta associação, Ramesh consegue um envolvimento maior do dançarino com o que está sendo apresentado no palco, e assim uma maior coerência com a complexidade e completude da dança clássica indiana.

Segundo Ramesh, nem todos os aprendizes de dança na Índia aprendem esta forma clássica devido a uma paixão pela arte do movimento. $\mathrm{Na}$ maioria das vezes, aprendem dança clássica indiana devido à sua importância histórica. Ou seja, muitas vezes o fator histórico é mais enfatizado que a própria dança. Do mesmo modo, fora da Índia os praticantes não têm conhecimento e entendimento desde repertório de movimento. O processo de consciência corporal provocado pela LMA ajuda os alunos a entenderem a relevância da dança em todos os seus contextos (ritual, histórico, cultural, social, etc.) através de um melhor entendimento do movimento em si mesmo. Assim, LMA transporta a dança clássica Indiana além do tempo e do espaço, tornando-a universal, encorajando a criatividade, melhorando a qualidade das apresentações, e abrindo novas possibilidades de aplicação desta forma de arte em outros campos, como o trabalho terapêutico, comunitário, etc. Assim, encontramos o novo ao revistar interculturalmente uma tradição antiga.

Na próxima sessão, apresento resumidamente algumas conexões entre LMA e Bharatanatyam, como percebido e organizado no trabalho de sala-deaula e no estúdio. Estas associações são organizadas em itens para facilitar a compreensão. No entanto, na prática, estes itens sobrepõem-se uns aos outros durante os exercícios, especialmente durante os adavus (unidades de dança pura, adicionadas umas às outras para criar uma composição de dança) ou praticando as danças ou partes delas.

\section{Análise associativa de Bharatanatyam e LMA}

1. Estabilização da pélvis e iniciação do movimento

Em Bharatanatyam, a pélvis permanece estável todo o tempo. Neste sentido, é bem distinto de quando realizamos as Escalas Espaciais de Laban, quando a pélvis não apenas se move, mas guia todo o movimento. Os Fundamentos Corporais criados por Irmgard Bartenieff, denominados de Bartenieff Fundamentals (BF), são um preparo para esta integração entre corpo e espaço a partir do centro do corpo. Quando realizamos as Escalas A ou B do Icosaedro (Fernandes, 2006), por exemplo, todo o corpo desenha percursos transversos (que atravessam os três planos - vertical, sagital e 
horizontal) guiados pelo cóccix, com rotação profunda nas duas articulações coxo-femorais. Através dos Fundamentos Corporais (BARTENIEFF, 1980), nos movemos com Suporte Muscular Interno a partir do ILIOPSOAS e dos músculos do assoalho pélvico, ativados pelo Suporte Respiratório.

Em Bharatanatyam, a pélvis também é o centro de energia, mas exatamente por isso ela permanence aparentemente imóvel, enquanto os chamados "membros principais" - pés, mãos, olhos, cabeça, pescoço e cintura - iniciam o movimento. Apesar dos movimentos não surgirem visivelmente da pélvis, é justamente esta estabilidade pélvica que apóia e permite os movimentos simultâneos e complexos.

Em uma aula de Bharatanatyam para iniciantes, quando os estudantes tentam estabilizar a pélvis e iniciar os movimentos pelos "membros principais", a tendência é tensionar a postura e prender a respiração, prestar atenção na periferia do corpo (pés, mãos, cabeça), perdendo o foco na iniciação central e, consequentemente, o suporte central e respiratório. Assim, usamos os Fundamentos Corporais de Bartenieff como aquecimento para Bharatanatyam, e os relembramos aos alunos enquanto dançam, trazendo a consciência para o Suporte Respiratório e Muscular Interno. Estes Princípios de Movimento desenvolvidos por Bartenieff, assim como as Conexões Ósseas, ajudam a estabilizar sem tensionar, facilitando a iniciação a partir do centro, mas de não de modo visível (Temas Mobilização/Estabilização e Função/Expressão em LMA).

As Conexões Ósseas na pélvis, ou entre a pélvis e outras Marcas Ósseas que ajudam nesta estabilização são: Trocanter-Trocanter, Trocanteres-CóccixSínfise Púbica (criando um losango na base da pélvis), Ísquios-Cóccix-Sínfise Púbica (criando outro losango), conectando estes losangos aos calcanhares e à cabeça. Estas linhas dinâmicas entre Marcas Ósseas irradiam do espaço interno para o espaço externo com Intenção Espacial, como será visto no próximo item.

\section{Postura básica de Bharatanatyam, com a coluna ereta}

Na postura básica de Bharatanatyam, as pernas e os pés estão em rotação externa, com os joelhos flexionados e calcanhares quase se tocando. Esta posição é denominada Aramandi. Os braços estão esticados para os lados na altura dos ombros, com os cotovelos para cima. Ou seja, os braços estão levemente rodados para dentro, com seu lado externo virado para cima até as pontas dos dedos, criando uma forma levemente arredondada a partir dos pulsos. Esta posição dos braços é denominada Natyarambeh. Não há nenhuma quebra na linha do braço na altura do pulso. Estes formam parted a longa linha para for a, e portanto não estão nem para baixo nem para cima. 
LMA ajuda a desenvolver esta postura, concedendo dinamicidade e fluidez sem perder a clareza das linhas e sua força. Através dos aquecimentos propostos em LMA, podemos manter esta posição de Bharatanatyam não como uma postura rígida, mas como transições dinâmicas, mesmo que muitas vezes enfatizemos poses específicas. A ênfase dos Bartenieff Fundamentals no nível baixo, com grande parte dos exercícios realizados no chão com peso passivo e fluxo livre, até sentar ou levantar em espiral, desenvolve um Alinhamento Dinâmico na vertical sem tensionar. Além dos Princípios já mencionados no item anterior, dois exercícios de Bartenieff são importantes em especial para preparar para a postura básica de Bharatanatyam: O Círculo dos Braços enquanto estamos deitados no chão em "X", associado ao Balanço dos Calcanhares, e as Escalas Espaciais de Laban (FERNANDES, 2006: 106, 107, 198-227).

Trabalhar em dupla nesta variação do Círculo dos Braços é ainda mais indicado. Enquanto um aluno está deitado em "X" com as costas no chão, o colega segura em seus calcanhares, auxiliando nos Balanços dos Calcanhares, mas também tem um de seus pés encostando levemente abaixo do cóccix do aluno. Assim, este conecta o movimento dos braços ao cóccix e aos calcanhares, ao invés dos ombros. A imagem é a de um varal de roupas: quando se puxa para baixo (a partir do cóccix, ísquios e calcanhares), os braços se elevam. Assim, na posição básica de Bharatanatyam, não pensamos em tentar manter os braços em Natyarambeh (o que muitas vezes chega a ser doloroso), mas sim no enraizamento a partir do cóccix, ísquios e calcanhares, que fazem com que os braços flutuem como folhas de um coqueiro. Isto é o que Irene Dowd chamou de "raízes para voar" (Taking Root to Fly, 1995).

Ao realizarem a posição básica de Bharatanatyam, os estudantes tendem a segurar seus braços tensionando na cintura escapular, o que acaba projetando os ombros para cima e para frente por causa da posição dos braços (levemente rodados para fora com cotovelos para cima). O exercício de Bartenieff descrito acima conecta a unidade superior e inferior do corpo. Então, ao invés de tensionar nos ombros, os alunos aprendem a mover ou estabilizar os braços a partir do Suporte Interno até a "raiz". Em LMA, isto naturalmente provocaria a rotação externa dos braços, num movimento como de concha, onde os braços esculpem o espaço tridimensionalmente como uma concha redonda de sorvete de bola. Nesta associação de LMA e Bharatanatyam, usa-se os músculos internos com uma intenção de rotação externa dos braços, enquanto aparentemente mantendo-os em uma leve rotação interna.

Os músculos do assoalho pélvico, tanto quanto o ILIOPSOAS são essenciais para manter este Suporte Interno. As "raízes" para os braços vêm da posição das pernas: uma rotação externa profunda nas articulações coxo- 
femorais, com os dois pés bem apoiados no chão (o peso distribuído igualmente em toda a sola dos pés). Enquanto os joelhos flexionam-se externamente, a pélvis se enraiza para baixo, conectando ísquios e calcanhares. Estes princípios de Bartenieff resolvem duas tendências problemáticas ao realizar a posição básica de Bharatanatyam: empurrar a pélvis para trás em uma forma convexa da coluna (lordosis), e segurar o peso do corpo nos joelhos flexionados, ao invés de segura-lo no Centro de Peso na pélvis.

Com este Suporte Interno e Conexões Ósseas, o corpo não apenas irradia com Intenção Espacial, mas usa o espaço como um parceiro ativo. A consciência das Marcas Ósseas e sua conectividade ajuda a perceber o espaço que puxa as Marcas em direção a diferentes pontos e percursos. Por exemplo, na forma cristalina do Octaedro, a dimensão horizontal puxa os braços para os lados a partir das escápulas (Conexões Escápula-Escápula, Escápula-Mão). Assim, ao invés de ter que manter os braços em uma posição difícil e provocar tensão desnecessária, usa-se o espaço para ativar as conexões internas e promover o alinhamento dinâmico no Natyarambeh. Já a dimensão vertical puxa a cabeça para cima e a "cauda" (cóccix) para baixo, ajudando a manter a coluna alongada e ereta e conectando unidades superior e inferior. Podemos inclusive imaginar um grande losango formado por linhas imaginárias e dinâmicas entre a cabeça, as escápulas e a cauda, cada uma irradiando em uma direção do espaço (alto, lados, baixo), e conectando-se com ísquios e calcanhares na unidade inferior, e com as mãos na superior. Assim, conecta-se todo o corpo dinamicamente, entre si e com o espaço, principalmente a partir do Octaedro.

Mas a associação entre corpo e espaço não é sempre assim tão óbvia. O Octaedro é visivelmente aplicável na posição básica de Bharatanatyam. Apesar dos movimentos desta dança acontecerem em diferentes vetores espaciais com pernas e braços, o torso tem apenas uma pequena ênfase nestes percursos, dependendo do adavu. Ou seja, o torso não se move através dos diferentes percursos e tensões espaciais, como nas Escalas Espaciais de Laban. Em Bharatanatyam, o torso tende a ficar estável, no Octaedro, e a maioria dos movimentos acontece através de percursos centrais ou periféricos. No entanto, quando vemos um dançarino de Bharatanatyam em cena, temos a impressão de que toda a Cinesfera (espaço ao redor do corpo) está sendo usada, inclusive os vetores do Icosaedro. Isto acontece porque a colocação dos membros no espaço resulta de uma forte concentração e irradiação de energia para dentro e para fora a partir do centro, como é conhecido em posturas de Bartenieff Fundamentals, sem necessitar de um movimento real e visível do Centro de Peso do corpo. Há uma complexa e constante relação entre interno e externo, corpo e espaço, energia visível e invisível. Isto fica claro no desenho de Robert Lawlor (1982) abaixo. 


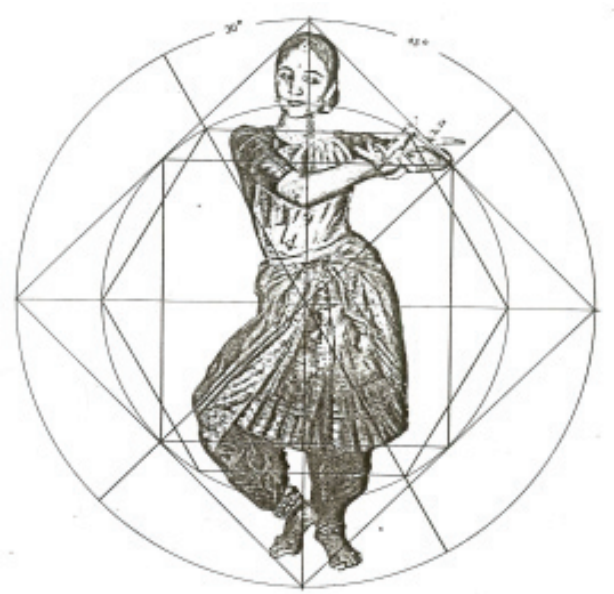

Figura 1. Dança clássica indiana em complexas relações geométricas com o espaço dinâmico.

Para alcançar este estado de interação energética entre corpo e espaço, realizamos as diferentes Escalas Espaciais de Laban, inclusive as Escalas A e B do Icosaedro, apesar destas - e exatamente porque estas - constituemse de percursos transversos tão distintos das tendências de Bharatanatyam. Em geral, ao realizarmos as Escalas Laban, movemos o Centro de Peso distanciando-nos do ponto denominado de Centro do Espaço, em direção a diferentes pontos. Aplicando o Tema Esforço/Recuperação (FERNANDES, 2006: 266), após diferentes Escalas Laban, os estudantes podem voltar para a posição vertical de Bharatanatyam sem tensionar. Nesta dança, estudantes sem aquecimento prévio tendem a tensionar para manterem-se na posição básica, tentando manter o torso parado e a coluna ereta. Mas quando, por exemplo, os alunos usam as Escalas A e B no aquecimento, eles naturalmente se recuperam de seus percursos transversos ao ficarem no eixo vertical, que passa a ser uma posição confortável, em pausa dinâmica, com todos aqueles pontos da Cinesfera ainda ativos.

O Tema Mobilidade/Estabilidade também é muito importante. A mobilidade tridimensional (com uso de rotação) de todo o corpo a partir da coluna (Escalas Laban) promove a estabilidade no torso em Bharatanatyam. Nesta dança, por sua vez, a estabilidade significa mobilidade em forma de energia, em todas as direções do espaço, a partir do Centro de Peso. Esta troca dinâmica acontece em cada exercício ou dança de Bharatanatyam, como será visto nos próximos itens. 
3. Ênfase de Bharatanatyam em fluxo controlado e padrões rítmicos rápidos

Como argumenta Cecily Dell (1977) fluxo controlado não significa estar tenso. A ênfase de Bharatanatyam em fluxo controlado pode ser associada a um controle bem claro sobre cada movimento, que são bem definidos em termos de Forma (em sua maioria Forma Direcional, apesar que novamente devemos pensar na Forma Fluida - órgãos, líquidos, etc. - como suporte e no aquecimento em Forma Tridimensional, já mencionado nas Escalas) (FERNANDES, 2006: 159-171).

Aqui temos o Tema Função/Expressão de maneira mais visível. O princípio do Suporte Respiratório, desenvolvido através dos Bartenieff Fundamentals, garante o fluxo de energia pelo corpo, em Correntes de Movimento. Quando a respiração (em especial, a segunda parte da expiração) dá início ao movimento, o fluxo controlado acontece como controle ao invés de tensão desnecessária.

Este suporte também ajuda o aluno a não se adiantar demais, o que tende a acontecer em movimentos realizados em ritmos muito rápidos. Nestes casos, devemos realizar as transições de uma pose para a outra bem rapidamente, alternando fluxo livre e controlado. Muitas vezes, o aluno tende a se tensionar quando não tem tempo suficiente para realizar os movimentos, e acaba por não realizá-los até o fim, e às vezes até termina um pouco antes do momento exato estipulado pelo ritmo. Por estes motivos, fluxo livre e Suporte Respiratório são instrumentos básicos para promover uma Conexão Corporal Total (HACKNEY, 1998) em sincronia exata com os ritmos. O princípio de LMA denominado Expressividade para a Conexão Corporal é, assim, incorporado aos complexos elementos expressivos de Bharatanatyam.

Além disso, trabalhando com a categoria Expressividade, podemos praticar as diferentes associações entre tempo e fluxo, desafiando a tendência muito comum de associar aceleração e controle. Pode-se explorar, por exemplo, acelerar com fluidez, ou desacelerar com controle. Esta análise nos mostra que o Estado Rítmico (peso e tempo), geralmente associada à Bharatanatyam, é apenas um de seus muitos aspectos expressivos.

4. Tattadavus.

Os tattadavus são exercícios básicos de aquecimento em Bharatanatyam, realizados também ao longo de todas as danças. Eles consistem em pisar 
firmemente no chão, a partir da elevação alternada das pernas, mantendo a pelvis estável e a coluna ereta. Eles se organizam em rítmos de um a oito, e cada um deles tem três velocidades, de vagarosa à rápida. Gradualmente, a cada movimento alternado das pernas, aprende-se a levantar cada pé mais rápido, mantendo o corpo no eixo vertical, ou seja, sem balançar para os lados ou para frente e para trás para compensar a alternância de apoio nas pernas.

A partir da posição básica, trazemos uma perna de cada vez, aproximando o calcanhar do ísquio, cada vez mais rodando as pernas externamente na coxo-femoral, enquanto trazemos a pélvis para baixo na Conexão Cóccix-Ísquios-Calcanhares (pois ela tende a subir junto com a perna). Isto é exatamente o contrário do que a maioria dos estudantes tende a fazer, a saber: ao transferir o peso de uma perna para a outra, ao invés de enfatizar a rotação na coxo-femoral e iniciar o movimento da perna nesta articulação, eles flexionam o joelho, iniciando nesta articulação, e enquanto a perna sobe, ao invés de enraizar pela "cauda", todo o corpo sobe e cria-se uma tensão desnecessária na pélvis para tentar estabilizar.

Para permitir o movimento dos pés sem transferir o peso ou excesso de movimento do torso, LMA e seus princípios de polaridades é crucial. Em primeiro lugar, podemos usar as Conexões Ósseas e a Intenção Espacial para imaginar, a partir do Suporte Respiratório, a "cauda" projeta-se para baixo e a cabeça para cima. Isto estabiliza a coluna e a pelvis, enraizando-a para permitir a rotação. Por outro lado, a rotação externa das pernas também estabiliza a pélvis (Mobilidade/Estabilidade). Estabilização não é tensão nem ausência de movimento: é mobilização interna, ativação profunda (através da respiração até a Rotação Gradual).

Então em Bharatanatyam usamos também o princípio de movimento Rotação Gradual, desenvolvido durante o aquecimento nos Bartenieff Fundamentals (BF) e Escalas. Alguns BF específicos usados neste caso são: PréElevação da Coxa, Pré-Elevação da Coxa com rotação externa, Transferência Frontal da Pélvis, Pré-Metade do Corpo (apenas com a parte de baixo do corpo), Metade do Corpo, Queda dos Joelhos com elevação lateral da coxa, com fluxo livre e impulso respiratório (vide FERNANDES, 2006: 70-108).

Apesar de realizados no chão, os $\mathrm{BF}$ mobilizam a pélvis para o movimento tridimensional no espaço, e também organizam o movimento, treinando o corpo para estabilizar a pélvis em qualquer posição, sempre a partir desta mobilidade estruturada. A Transferência Frontal da Pélvis, por exemplo, realizada no chão, conecta as unidades alta e baixa do corpo, 
desenvolvendo Correntes de Movimento através do Suporte Respiratório. Isto facilita a realização dos tattadavus (realizados em pé), sem perder o equilíbrio e a postura geral (como por exemplo balançando para frente e para trás ou para os lados pela falta de apoio muscular profundo nas diferentes dimensões). A Transferência Frontal da Pélvis também ajuda a encontrar o Centro de Peso, facilitando a postura quando estamos de pé. Assim, ao realizar os tattadavus, podemos deixar a pélvis descansar para baixo, ao invés de empurrá-la para frente ou para trás, quebrando na coluna lombar.

Os outros BF mencionados ajudam a perceber o movimento fluido das pernas a partir da respiração ativando a articulação coxo-femoral, alternando esquerda e direita, aprendendo a coordenar os lados em termos de estabilidade e mobilidade. Todos aqueles exercícios estruturam o movimento das pernas, a estabilização da pélvis, a rotação externa da articulação coxo-femoral (especialmente a Pré-Metade do Corpo e a Metade do Corpo), e as fortes batidas dos pés no chão (tattadavus) (especialmente a Elevação da Coxa com diferentes qualidades expressivas, conectando ísquios e calcanhares a partir da respiração).

Quando aprendemos a Elevação da Coxa, somos estimulados a pensar nas duas pernas ao mesmo tempo, apesar de apenas uma estar se movendo. Imaginamos, por exemplo, que o ar da expiração sai pelo ísquio da perna em repouso, o que ajuda a estabilizá-la para apoiar a mobilidade da outra perna. Esta é uma abordagem interessante, pois tendemos a nos concentrar apenas nas partes do corpo que se movem, perdendo assim nossa dinâmica entre estabilidade e mobilidade. O mesmo princípio se aplica ao realizarmos os tattadavus, pois temos a mesma organização corporal: movemos apenas a unidade inferior do corpo (organização homóloga), e apenas um dos lados (organização parcialmente homolateral). Ao realizarmos os tattadavus, não devemos nos concentrar apenas na perna que se move, mas de fato é recomendável manter o foco na rotação (cada vez mais) externa da perna de apoio, responsável por estabilizar a pélvis e facilitar a mobilização da outra perna. É uma maneira bem estimulante de se mover, ultrapassando dicotomias entre passivo e ativo, assim como a ênfase ocidental na atividade e no movimento.

Sob esta perspectiva do diálogo e da troca, também podemos usar Bharatanatyam para ajudar a desenvolver princípios de movimento de LMA. Por exemplo, tenho percebido que não apenas os BF ajudam na Conexão Ísquios-Calcanhares, facilitando nos tattadavus; mas também a prática dos tattadavus ajuda os alunos a desenvolverem esta e outras Conexões Ósseas, assim como a Intenção Espacial. 
Um detalhe importante destes exercícios são as batidas no chão com os pés. Não queremos marchar como soldados, ou nos machucar socando o chão com os pés. Muitas vezes se pensa que as batidas são fortes por causa do som produzido. No entanto, sua qualidade principal é um fluxo continuo de pulo, como um elástico que bate e volta. É como bater as palmas das mãos: a ênfase está no movimento de aproximar e afastar as mãos, mais do que propriamente em bater uma mão contra a outra, o que geraria um som seco e sem ressonância. Então a ênfase dos passos em Bharatanatyam é, de fato, para cima, pulando de volta do chão e alternando entre peso forte e leve. Isto ativa todo o corpo, com um efeito direto na expressividade do dançarino (Função/ Expressão). Aqui, novamente vemos que uma análise cuidadosa, resultante da prática e da observação, pode reveler aspectos da dança muitas vezes diferentes de idéias pré-concebidas (como por exemplo associar Bharatanatyam apenas a peso forte e fluxo controlado).

5. Organização de Bharatanatyam em termos de complexidade crescente

No Natya Shastra, considerado o Veda das artes cênicas indianas (Muni, 200 b.C.), a dança clássica Indiana é dividida em Indian Nritta (dança abstrata), Nritya (Abhinaya ou dança expressiva) e Natya (teatro). A divisão atualizada apresenta as seguintes categorias: Nritta (dança pura ou abstrata), Abhinaya (dança expressiva, geralmente contando histórias da mitologia hindu através de gestos das mãos, expressões faciais, etc.), e Nritya (uma combinação das duas anteriores). $\mathrm{O}$ treinamento começa com dança abstrata, gradualmente indo para dança expressiva e então para combinações das duas. Apenas após uma base segura de dança abstrata, o aluno é introduzido às nuances da dança expressiva.

A dança abstrata é constituída de Adavus - unidades de dança pura; "exercícios" que são gradualmente adicionados uns aos outros em coreografias complexas (vide Van Zile 1993; Kothari 1979; Sarabhai 1996). No treinamento clássico, estes exercícios são aprendidos em aula durante vários anos, seguindo uma ordem estipulada tradicionalmente. Ao fazermos uma análise em termos de Laban/Bartenieff, observamos que esta ordem segue uma complexidade crescente em termos de Corpo-Forma-Expressividade-Espaço (categorias de LMA). Em termos de Padrões Neurológicos Básicos (COHEN, 1993), exercícios começam em uma organização Homóloga (superior-inferior), e vão para Homolateral (metade do corpo), e posteriormente para Contralateral (lados cruzados), e para combinações de diferentes organizações. Ao realizarmos os Padrões Neurológicos Básicos, tanto nos Fundamentos de Bartenieff quanto nos exercícios desenvolvidos por sua discípula Bonnie Bainbridge Cohen, 
ativamos conexões neuromusculares profundas que facilitam sua aplicação nas complexas combinações de Bharatanatyam. Muitas vezes, associo exercícios selecionados de Bartenieff e de Cohen, de acordo com a Organização Corporal, como preparatórios para algum adavu específico. Por exemplo, enfatizo a Metade do Corpo e suas variações antes de uma aula onde serão estudados o primeiro e segundo nattadavus. Estes são exercícios ensinados logo após os tattadavus, e consistem em abrir a perna e o braço do mesmo lado na dimensão horizontal enquanto o outro lado estabiliza na posição básica, e então troca-se os lados.

Ao praticar os adavus, a Conexão Olho-Mão é particularmente importante, porque estes exercícios implicam na congruência de movimento entre cabeça e mãos, guiados pelo foco do olho. Bharatanatyam tem todo um sistema para nomear cada movimento de cada parte do corpo, e isto também inclui os olhos, que são considerados um membro principal. Existem oito movimentos para os olhos em Bharatanatyam, como se eles deslizassem ao longo de vetores espaciais. Isto é muito interessante, pois nas técnicas ocidentais os olhos não são tão enfatizados. Então tenho praticado, por exemplo, realizar Escalas Espaciais de Laban apenas com os olhos e, quando necessário, pequenos movimentos da cabeça e pescoço. Como parte da Integração Corporal Total através dos Fundamentos Bartenieff (HACKNEY, 1998), os olhos são um elemento importante na conexão interno-externo, na Intenção Espacial e no sequenciamento do movimento. O Fundamento Bartenieff denominado de Círculo do Braço (FERNANDES, 2006: 102-107) fortalece a Conexão OlhoMão, desenvolve o foco do olhar e a associação da visão com a percepção e consciência interna.

Em termos de vetores espaciais, os adavus começam usando uma ou duas dimensões do Octaedro, indo para um ou dois pontos dos planos do Icosaedro e então para diagonais do Cubo e, posteriormente, para complexas combinações das três figuras geométricas. Como no caso das Organizações Corporais, utilize formas cristalinas específicas e suas escalas como preparatórias para exercícios selecionados de Bharatanatyam. Por exemplo, no caso de alunos avançados de interpretação, fazemos escalas inteiras do Icosaedro, com fluidez de movimento. Em seguida, marcamos claramente alguns pontos no espaço (selecionados por fazerem parte do adavu escolhido), percebendo a iniciação central (a partir do Centro de Peso) do movimento no espaço. Exploramos então estes pontos com variações de Padrões Neurológicos, Tensão ou Percurso Espacial, indo e vindo nestas direções. Apenas então ensino o adavu, sempre referindo-me à experiência anterior em Harmonia Espacial. 
Apesar da categoria Espaço ser incluída no trabalho de aula desde o início, em Técnica de Corpo para Cena I, ela é tratada mais diretamente, como enfoque principal, apenas a partir do segundo semestre, em Técnica II. A ênfase do primeiro semestre de corpo que ministro na UFBA é nos Princípios de Movimento de Bartenieff, na Forma e na Expressividade. Todas estas continuam a ser revisitadas nos outros 3 semestres, em especial a Expressividade, mas também a associação das três categorias a partir da introdução da quarta (Espaço). No entanto, o Icosaedro em geral só é trabalhado por completo no terceiro semestre, pois seus percursos transversos em escalas de doze pontos exigem muita noção do espaço, sem perder (e de fato estimulando) as conexões internas. Para tanto, no segundo semestre, enfatizo o Octaedro e o Cubo, cujas escalas acontecem em percursos centrais, garantindo uma percepção mais clara do corpo no espaço dinâmico.

Assim sendo, no terceiro semestre, ao ensinar cada um dos três planos do Icosaedro e antes de ensinar suas escalas complexas, utilizo alguns adavus com aqueles pontos, para dar clareza no espaço. Assim os alunos percebem que Harmonia Espacial não é um arcabouço abstrato e matemático, mas sim de Integração Corporal Total, tanto quanto Bharatanatyam. A partir da associação desta dança com LMA, as linhas de/em movimento ficam mais precisas no espaço, qualidade fundamental em Bharatanatyam. A partir desta conexão entre corpo e espaço, mapeando a dança, podemos então nos concentrar em ritmos complexos, gestos das mãos, etc.

Em geral, não ensino os adavus para alunos iniciantes de interpretação, porque primeiro enfatizo a repadronização, ou seja, a construção da Integração Corporal Total através dos Fundamentos Bartenieff. Mas já ao final do primeiro semestre, é possível ensinar a posição básica e os tattadavus, que ajudam no enraizamento e naquela integração, aplicando todos os Princípios de Movimento em um só exercício.

Em termos de Forma ou Relacionamento, o aprendizado de Bharatanatyam também segue uma ordem de complexidade crescente. Assim, a maioria dos exercícios acontece em Forma Direcional Linear ou Arcada, com flexão/extensão e abdução/adução, e aos poucos incluindo a Forma Tridimensional com rotação à medida em que os exercícios se tornam mais avançados. O suporte da Forma Fluida também é muito importante: o volume interno do corpo é o que permite a criação de formas no espaço, e não devemos esquecer que Bharatanatyam encontra grande parte de sua inspiração em poses de esculturas de templos hinduístas. A prática dos três Modos de Mudança de Forma de LMA facilita aos alunos incorporarem aquelas figuras de pedra, em movimento dinâmico. Afinal, Forma em LMA é um conceito em movimento, por isso denominado de Modos de Mudança de Forma. 
Em termos de qualidades expressivas, padrões rítmicos ficam cada vez mais detalhados ao longo do treinamento, exigindo mais e mais prontidão e agilidade, assim como uma habilidade crescente para conectar movimentos em frases de movimento cada vez mais complexas, alternando esforço e recuperação. Os nattadavus concentram-se mais em combinações expressivas simples (como direto e acelerado seguido de controlado e acelerado) em fraseados acentuados (formados por uma série de acentos distribuídos homogeneamente ao longo da frase de movimentos). Gradualmente, enquanto exercícios se tornam mais elaborados em termos de Corpo e Espaço, há necessidade de maior variação expressiva, até atingir seqüências de grande demanda, onde é necessária a sabedoria para distribuir a energia ao longo de Frases Expressivas complexas. Apenas após um longo período deste treinamento abstrato, o estudante começa a desenvolver as sutis nuances da dança expressiva (item que será discutido posteriormente). Desde o início do treinamento em Bharatanatyam, estudantes são estimulados a sorrirem enquanto realizam unidades de dança abstrata, mas apenas ao aprenderem dança expressiva eles começam a associar ambas tendências - da dança abstrata e da dança expressiva -, até que sejam capazes de realizar danças que alternem as duas, ou dançar todo um programa de Bharatanatyam com as três categorias (Nritta, Abhinaya e Nritya).

6. Complexidade e simultaneidade de movimentos de Bharatanatyam, com muitos detalhes e ornamentos

Apesar do aprendizado de Bharatanatyam seguir uma ordem de complexidade crescente, desde o início requer entrega total. Para realizarmos apenas os tattadavus, por exemplo, muita concentração é necessária. Ao realizarmos os primeiros adavus, denominados nattadavus, já usamos mudanças de gesto e de postura simultaneamente, e a expressão facial não deve estar tensa. Claro que no ensino para iniciantes estes adavus são aprendidos separadamente. Assim os alunos aprendem primeiramente a dar um passo para o lado sem transferir o peso para a perna que se afasta do centro, mas mantê-lo na perna que permanece no centro. Só mais tarde aprende-se os movimentos dos braços, e então adiciona-se os dos olhos. Então cada exercício deve ser praticado como uma unidade inteira, coerentemente com o caráter complexo de Bharatanatyam. A prática desta dança exige e desenvolve concentração, a percepção e consciência do/no movimento.

Podemos usar LMA, como a Integração Corporal Total, para fundir movimento do centro e da periferia, função e expressão, gesto e postura, movimento pelo espaço em diferentes vetores e estabilidade no torso, etc. A partir do Suporte respiratório e Muscular Interno, e das Correntes de Movimento através das diferentes Organizações Corporais e apoiado nas 
Conexões Ósseas, gradualmente construímos a Integração Corporal Total até vetores espaciais claros (Intenção Espacial). Podemos contar com esta estrutura para conectar diferentes partes do corpo nos vários movimentos simultâneos de Bharatanatyam. Como recomendado por Ramesh, uma vez que temos as linhas bem definidas (conexão Corpo-Espaço), podemos enfatizar expressões faciais, ornamentos e inúmeros detalhes da dança (Função/ Expressão).

LMA também nos concede os instrumentos para compreender Bharatanatyam, observando suas complexas combinações e facilitando seguir determinados movimentos quando necessário, sem perder a conexão interna. Padrões Neurológicos Básicos ajudam o aluno a perceber em ação (COHEN, 1993) alguns "truques" que embelezam a dança e a tornam mais complexa. Lembro-me de assistir alunos avançados se enganarem repetidas vezes no mesmo ponto de um adavu, trocando o pé com o qual deviam dar o passo e marcar o ritmo (já que o passo em Bharatanatyam faz ritmos contra o chão). Ao analisar aquele adavu, notei que era constituído principalmente de movimentos homolaterais e que, em um momento de ênfase, com acento expressivo, havia um pequeno movimento contralateral (aquele que os alunos tendiam a trocar). Este movimento contralateral era um belo momento de climax na frase, mas muito rápido para ser realizado facilmente em meio a outra Organização Corporal. Identificando e aprendendo esta nuance, pude prestar maior atenção ao realizar o exercício, e conceder-lhe a devida ênfase.

\section{Rasa, dança expressiva e expressões faciais}

Rasa refere-se a água, suco, essência, líquido saboroso e, no contexto filosófico da Índia, à experiência estética do ator e, principalmente, do público (MEYER-DINKGRAEFE, 1994: 85). Rasa pode ser traduzido para "sentimento", classificado pelo Natya Shastra em longas listas de "estados transitórios" diferentes, com suas subdivisões. Comparo este conceito de rasa à Eucinética de Laban, na qual combinações de atitudes internas provoca uma expressão que chega ao público. Ele também chamou estas combinações de "estados", cuja característica principal é a mutabilidade - gradações entre extremos de um fator expressivo específico. Enquanto peso é associado à sensação, tempo à intuição, e espaço (foco) ao pensamento (MALETIC, 1987: 203-2 17), fluxo ou fluência associa-se à emoção e é subliminar aos outros três fatores.

Fluxo é a base de todo movimento, como uma tensão subliminar e um impulso inicial presente, por exemplo, em todas as funções vitais. Assim, fluxo pode ser associado à Forma Fluida, ou seja, a relação do corpo consigo 
mesmo, percebendo seu próprio volume e movendo-se a partir da respiração, dos órgãos e líquidos corporais. Bonnie Bainbridge Cohen (1993), discípula de Bartenieff, tem provado a importância do "Sistema Fluido do Corpo" - fluido celular e intercelular, sangue, linfa, líquido cérebro-espinhal, líquido sinuvial - na expressividade, como já era associado no conceito védico de rasa.

Os Princípios de Movimento de Bartenieff - em especial a Expressividade para a Conexão Corporal - ajudam a ativar a prontidão interna, conectando os movimentos através do fluxo, mas também através dos outros três fatores (foco, peso e tempo). Isto facilita dançar Bharatanatyam sem tensionar. A partir do Suporte Respiratório e da Forma Fluida (por exemplo, usando exercícios criados por Cohen), ativamos a fluidez corporal para sentir (relacionado a fluxo). A partir destas experiências, podemos trabalhar com a categoria Expressividade, em estados e impulsos, posteriormente acrescentando estas combinações às formas cristalinas, nas Escalas Espaciais. Esta é uma preparação para rasa e para as diferentes expressões faciais de Bharatanatyam.

As nove principais emoções estéticas de Bharatanatyam e também de Kathakali estão presentes nas diferentes expressões faciais, acompanhadas por gestos e posturas específicos. São elas: amor (Shringara), coragem (Vira), simpatia/compaixão (Karuna), admiração (Abdutha), risada (Hasia), medo (Bhaya), nojo (Bibatsia), raiva (Raudra), e tranquilidade (Shantam). Se pedimos aos estudantes para expressarem estas faces logo de início, eles podem demonstrar resistência, ou ter dificuldade, porque passamos nossas vidas tentando esconder nossas emoções ou aprendendo a dissimulá-las. Então podemos usar exercícios de Expressividade de LMA para nos reconectar com estados emocionais, inicialmente em todo o corpo e, posteriormente, concentrados na face.

Obviamente, não há uma correspondência exata entre as combinações expressivas de LMA e os estados emocionais de Bharatanatyam, mas um pode ajudar a achar o outro. Por exemplo, Raudra (raiva) possui principalmente peso forte, associado a outras qualidades condensadas, como acelerado, ou controlado, etc. Já Shringara (amor) inclui principalmente o peso leve, com outras qualidades indulgentes ou entregues, como desacelerado, livre ou multifoco. 


\section{Considerações finais}

Como vimos, LMA e Bharatanatyam podem ter princípios de movimento aparentemente opostos, mas é exatamente esta associação de diferenças que facilita o aprendizado e a apresentação das duas formas cênicas. Este é um importante eixo do material de LMA: transformar polaridades em relações dinâmicas. Isto pode ser visto em todo o material de LMA, em temas como Interno/Externo, Esforço/Recuperação, qualidades dinâmicas como forte/ leve, livre/contido, etc. Ao invés de conceitos opostos, trabalhamos sempre com movimento ao longo de polaridades, em transições. Desta forma, LMA concede uma estrutura para Bharatanatyam, e vice-versa.

Enquanto em LMA, assim como em técnicas advindas da dança moderna, tendemos a enfocar a Irradiação e a Iniciação Central, Bharatanatyam enfoca a Iniciação Medial e Periférica, a partir dos "membros principais" pés, mãos, olhos, cabeça, pescoço e cintura. Assim, por exemplo, o enfoque na postura do primeiro é complementado pelo enfoque em gestos e expressões faciais do segundo. A partir desta associação, começamos a perceber um fato que muitas vezes passa desapercebido: expressões faciais e gestos manuais nascem de posições com o corpo todo, em composições complexas de movimento, no que Warren Lamb (1979) chamou de Imersão Gesto-Postura.

Ao dançar Bharatanatyam, em especial associado à LMA, sentimos que as expressões faciais e gestos das mãos emergem da coluna e do corpo como um todo para o espaço dinâmico, integrando interno e externo. Isto acontece porque estes gestos não são casuais:

A linguagem gestual da dança hinduista traça a origem do Tajur Veda, a forma simbólica dos ritos de sacrifício. Os gestos foram inicialmente esquematizados para evocar estados espirituais através de atos cerimoniais imaginariamente realizados como ritual. Como uma ideografia complexa de símbolos representando os deuses e seus emblemas, o paraíso e a terra, e as regiões inferiores, os cinco elementos, o sol e a lua de significado místico -, eram dados forma pictórica como poses manuais simbólicas no ritual védico. (DEVI, 2002: 38)

Esta integração entre corpo-emoção-espírito ou soma - daí Educação Somática -, demonstra a coerência da associação realizada neste projeto. Demonstramos que Bharatanatyam, assim como LMA, é um complexo sistema de práticas e conceitos para uma formação integrada. Nos dois métodos, o 
corpo é associado ao cosmo, numa abordagem simultaneamente científica e artística, onde poesia, palavras, sons, música, dança, arquitetura e escultura criam um "desenho preenchido de consciência da totalidade" (VATSYAYAN, 1997: 41).

\section{Referências}

BARTENIEFF, Irmgard. Body Movement: Coping with the Environment. Langhorne: Gordon and Breach, 1980.

DELL, Cecily. A Primer for Movement Description. New York: Dance Notation Bureau, 1977.

DEVI, Ragini. Dance Dialects of India. Nova Deli: Motilal Banarsidass Publishers, 2002.

DOWD, Irene. Taking Root to Fly. Articles on Functional Anatomy. New York: Contact Collaborations, 1995.

COHEN, Bonnie Bainbridge. Sensing, Feeling, and Action: The Experiential Anatomy of Body-Mind Centering. Northampton: Contact Editions, 1993.

ERDMAN, Joan L. "Dance Discourses: Rethinking the History of the Oriental Dance." In: Gay Morris, ed. Moving Words. Re-Writing Dance. Londres: Routledge, 1996, 288-305.

FERNANDES, Ciane. O Corpo em Movimento: O Sistema Laban/Bartenieff na Formação e Pesquisa em Artes Cênicas. São Paulo: Annablume, 2006. $2^{\text {a }}$ ed.

HACKNEY, Peggy. Making Connections. Total Body Integration Through Bartenieff Fundamentals. Amsterdã: Gordon and Breach Publishers, 1998.

KOTHARI, Sunil, ed. Bharata Natyam: Indian Classical Dance Art. Bombay: Marg Publications, 1979.

LABAN, Rudolf. Domínio do Movimento. São Paulo: Summus, 1978.

LAMB, W. and WATSON, E. Body Code: The Meaning in Movement. Londres: Routledge and Kegan Paul, 1979.

LAWLOR, Robert. Sacred Geometry. Philosophy and Practice. Londres: Thames and Hudson, 1982.

MALETIC, Vera. Body-Space-Expression: The Development of Rudolf Laban's Movement and Dance Concepts. Berlim: Mounton de Gruyter, 1987.

MEYER-DINKGRAEFE, Daniel. Consciousness and the Actor: A Reassessment of Western and Indian Approaches to the Actor's Emotional Involvement from the Perspective of Vedic Psychology. Frankfurt: Peter Lang, 1996.

MUNI, Bharata. The Natya Shastra - The Encyclopaedia of the Performing Arts. Delhi: Sri Satguru Publications.

OSBORNE, Claire. "The Innovations and Influence of Rudolf Laban on the Development of Dance in Higher Education During the Weimar Period (1917-1933)", in Working Papers v.2 (Londres: Laban Centre, 1989), 83-102. 
SARABHAI, M. Understanding Bharata Natyam. Gujarat, Índia: Darpana, 1996.

VAN ZILE, Judy. "Characteristics of Nrtta in Bharata Natyam." In: George Kliger, Bharata Natyam in Cultural Perspective. Nova Delhi: Manohar American Institute of Indian Studies, 1993.

VATSYAYAN, Kapila. The Square and the Circle of the Indian Arts. Nova Deli: Abhinav, 1997. 